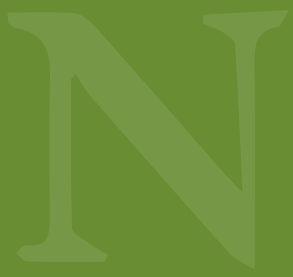

SEccion: Problemas espaciales contemporaneos
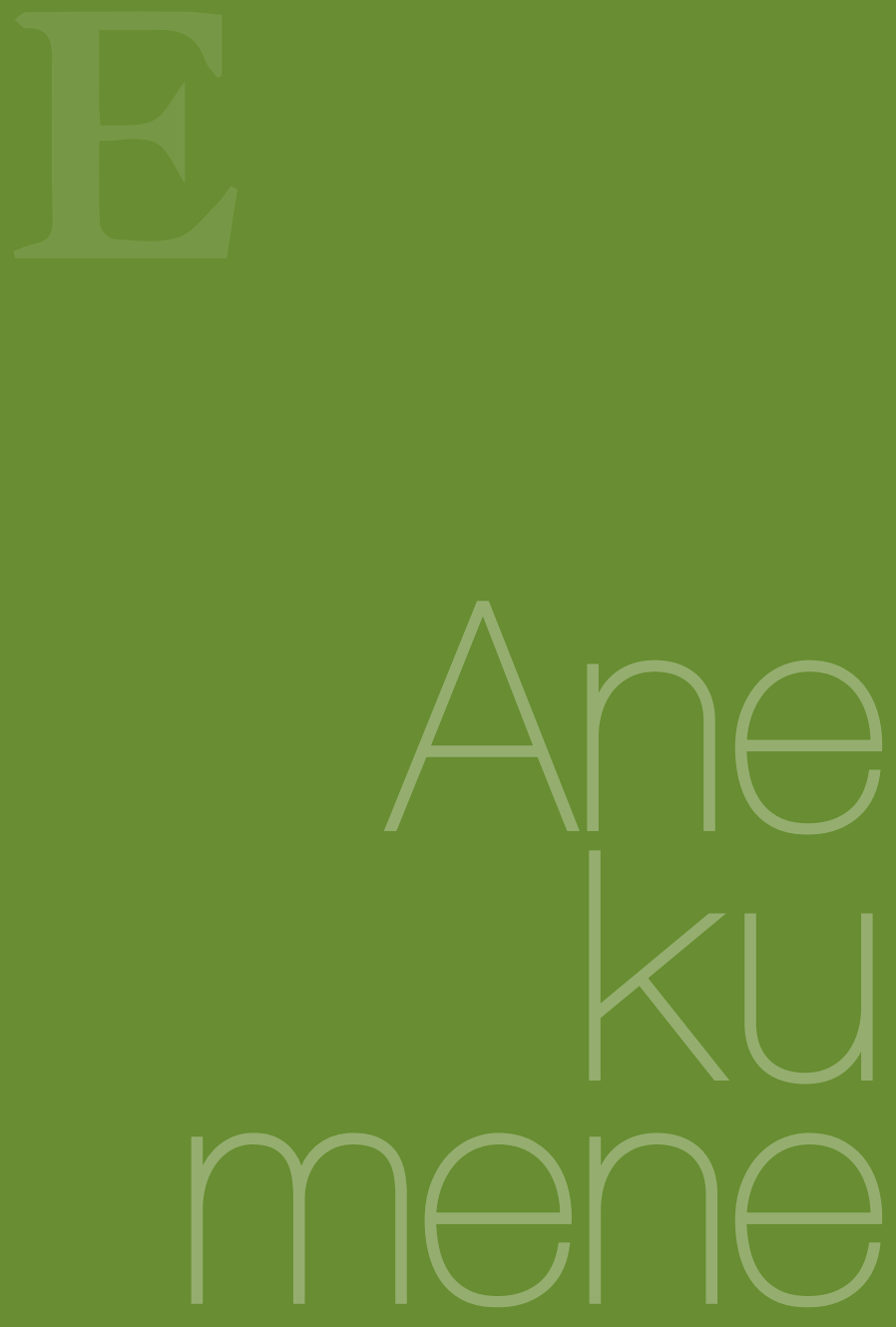


\section{Vida cotidiana y configuración espacial en la novela Señor que no conoce la luna*}

\section{Daily Life and Spatial Configuration in the Novel Señor que no conoce la luna}

\section{Vida diária e configuração espacial na novela Señor que no conoce la luna}

Sandra Lorena Ramírez Moreno**

\section{Resumen}

Este artículo analiza las relaciones que determinan la manera de vivenciar por parte de los protagonistas de la novela de Evelio Rosero Señor que no conoce la luna (2011) los lugares en los cuales se desarrolla las trama novelesca, para tal fin toma tres escenarios: la casa, el armario y la calle. La línea transversal del análisis, es la vivencia cotidiana de los personajes, y la manera como se establecen las relaciones de acuerdo a una dialéctica del dentro y del afuera. La mirada a partir de lo literario permite dar cuenta de la configuración espacial a partir de la cotidianidad de los habitantes de un lugar; en este caso las relaciones se establecen con la ciudad que emerge en la modernidad.

\section{Palabras clave}

Habitar; espacio; vida cotidiana; experiencia y ciudad moderna

\footnotetext{
* Artículo derivado de la investigación "El hombre y la ciudad moderna: una aproximación desde la novela Señor que no conoce la luna”- Incluir Investigación monográfica en el programa de Licenciatura en Educación con énfasis ciencias sociales - UDFJC - dirigida por la profesora Nubia Moreno Lache - Grupo Geopaideia

** Licenciada en Educación Básica con énfasis en Ciencias Sociales de la Universidad Distrital Francisco José de Caldas, estudiante de maestría en Estudios Literarios de la Universidad Nacional de Colombia y docente de Ciencias Sociales del Gimnasio Vermont.
} 
Vida cotidiana y configuración espacial en la novela

Señor que no conoce la luna

Sandra Lorena Ramírez Moreno /

\section{Abstract}

This article analyzes the relationships that determine the way the protagonists of Señor que no conoce la luna (2011), by Evelio Rosero, experience the places where the novel's plot takes place. To this purpose, three scenarios are taken into account: the house, the closet, and the street. The main line of analysis is the day-to-day experience of the characters, and the way they establish relationships according to the dialectics of the inside and the outside. An overview from literature accounts for the spatial configuration from the everyday life of the inhabitants of a place; in this case, the relationships are established with the emergence of the modern city.

\section{Resumo}

Este artigo analisa os relacionamentos que determinam a forma como os protagonistas do romance de Evelio Rosero, Señor que no conoce la luna, (2011), descobrem os lugares em que ocorre a história; para este fim, tomam-se três cenários: a casa, o armário e a rua. A linha transversal de análise é a experiência diária dos personagens e a forma como os relacionamentos são estabelecidos de acordo com uma dialética de dentro e de fora. $\mathrm{O}$ olhar desde o ponto de vista literário permite dar conta da configuração espacial da vida diária dos habitantes de um lugar; neste caso, as relações são estabelecidas com a cidade que emerge na modernidade.

\section{Keywords}

Inhabiting; space; daily life; experience and modern city

\section{Palavras-chave}

Habitar; espaço; vida diária; experiência e cidade moderna. 


\section{"El delirio de un extraño personaje frente al mundo moderno"}

Esta frase acompaña la primera edición de la novela Señor que no conoce la Luna ${ }^{1}$, aparece inmediatamente después del título y permite al lector hacerse una idea sobre el cuestionamiento central de la obra. Es una novela delirante, en la que el lector se apropia de la voz del personaje sin nombre (el Desnudo) y recorre cada espacio atestiguando las situaciones extremas vividas por este. Los escenarios no corresponden a una ciudad específica, aun así, no hay una sensación de alejamiento, pues el sistema de relaciones que se estructura dentro de los espacios contiene similitudes respecto a las relaciones mismas que subyacen a la ciudad habitada por el lector.

La estructura del relato presenta características particulares que hacen de esta obra una novela poco convencional; la presencia escasa de diálogos, de pocos personajes y la utilización de una sola voz narrativa hacen que cada párrafo se asemeje a un monologo desesperado nutrido de reflexiones, disgustos y esperanzas, proferidos por quien se distingue como el Desnudo. La espacialidad se enlaza con las vivencias conflictivas sufridas por dos grupos de personajes - los vestidos y los desnudosacontecidas en tres escenarios: una casa (habitada por los desnudos), la calle (habitada por los vestidos) y un armario (habitado por el Desnudo).

Lo fundamental para la narración es la situación del hombre en medio de lo que parece ser un caos "organizado" y las relaciones existentes a partir de situaciones particulares, por lo cual a partir de la novela es posible realizar una comprensión general de los fenómenos espaciales que surgen siempre a la sombra de las relaciones sociales o de las experiencias cotidianas.

\section{Vida cotidiana y espacio en la novela}

Las relaciones sociales que se configuran en la vida cotidiana pueden darse en dos vías, como la consolidación de una estructura social en las acciones del diario vivir o como resistencia de esas dinámicas impuestas, es en la cotidianidad donde el hombre enfrenta al otro y todo lo que este encierra. Las prácticas cotidianas, asimismo, determinan la manera como los hombres perciben y vivencian los lugares. Según Yi-Fu Tuan (2007), "no hay dos personas que perciban de forma precisamente igual la realidad, ni dos grupos sociales" (p. 15), por lo que la diversidad de percepción enriquece la manera como es entendido el lugar.

La configuración espacial, a partir de estas características, entiende el espacio más allá de su estructura física y privilegia el papel del hombre como constructor de significados. Otto Bollnow (1969) propone la categoría de espacio vivenciado para darle centralidad a esa vida cotidiana, cuya exploración y análisis implica retomar los fundamentos de la vida que habitualmente pasan desapercibidos. Se está frente a un espacio ligado al hombre por relaciones vitales, dado esto, cada lugar dentro del espacio tiene una significación diferente para el hombre, "entonces, el espacio vivido estará impregnado por una serie de significaciones como estructura y ordenación que son expresión de cada grupo social y de cada individuo" (Rincón, 2007, p. 5).

El espacio vivenciado que encierra múltiples significaciones se hace presente en la obra literaria, la libertad que ofrece la novela de Rosero, al no desarrollarse en una ciudad conocida, facilita la identificación de diferentes elementos, como los lazos que unen al hombre con cierto lugar, cuya intensidad es variable, un ejemplo de ello es el lugar nombrado como "la casa" dentro de la narración, o "el armario", donde hacen presencia niveles de apego, resistencia, e incluso la manifestación de un desligue total con el lugar.

\section{El espacio vivenciado en Señor que no conoce la luna}

El espacio en la obra literaria aparece como espacio vivido: encierra experiencias, encuentros, desencuentros y sensaciones, y permite una comunicación de doble vía entre la experiencia cotidiana del personaje y el lugar donde se desarrolla. Todo esto genera una construcción amplia de significados que viajan entre la reafirmación o la reconfiguración; en palabras de Fernando Aínsa:

[...] el texto/textura de la narrativa que se ha ido apropiando del espacio - sabanas y llanos, selvas y montañas, barrios y ciudades-integra conjunto de símbolos con un "sentido común", un mundo de significaciones suficiente para permitir tanto la reconstrucción de los espacios de origen como la recuperación de un lugar privilegiado del "habitar". (2006, p. 11).

Esos "mundos de significaciones" se construyen en la oportunidad que ofrece el desenvolvimiento de la vida cotidiana de los personajes, por medio de experimentación individual o grupal, en el desenvolvimiento de las actividades comunes, en la conflictividad o no de las relaciones personales, y por último, pero no menos importante, en la posibilidad de habitar dichos lugares.

Entonces, para el análisis de los lugares propuestos (casa, armario y calle) se toman las percepciones significativas que giran alrededor de estos, pero también las prácticas cotidianas que "dan cuenta del sujeto tal y como se comporta y actúa en el espacio y de los significados para él y los otros" (Lindón, 2000, p. 12), por lo que los movimientos propios de

1 La primera edición de la novela es presentada al público en el año 1992. 
la vida cotidiana y situaciones extremas enfrentadas por los personajes tendrán un valor determinante en la manera como se configuran esos espacios. En palabras de Sañudo:

El espacio se convierte en la manera como cada persona entiende su habitar, y este es el resultado de una serie de experiencias humanas que van mostrando cómo el espacio mismo se convierte en un patrón de crecimiento organizacional que determina las maneras en que cada individuo entiende su intimidad. (2013, p. 226).

Experiencias, significados, construcciones cotidianas personales o grupales, van a permitir escudriñar los significados de cada lugar propuesto por la novela, y van a generar la oportunidad de, a partir de diversas visiones, acercarse a dichos lugares mediante parámetros diferentes, posibilidad siempre abierta gracias a los personajes de la novela y a la forma como se desarrollan los hechos. Del mismo modo, la identificación a partir de sensaciones va a permitir categorizar las vivencias de lugar, pues, como se mencionaba en párrafos anteriores, estas desempeñan un papel fundamental en develar todo lo que se teje en la configuración espacial.

El análisis de la espacialidad dentro de la novela, como se ha mencionado, privilegia tres lugares presentes en la narración: la casa, el armario y la calle. El análisis va a generar interrogantes que van a cuestionar o afirmar nociones ligadas a estos espacios, siempre en relación con la vivencia del espacio a partir de la cotidianidad.

\section{La casa: desarraigo y desprotección}

La casa, en la novela, es un lugar grande que cuenta con cimientos antiguos y con grandes galerías y patios, con estas pocas características físicas es posible deducir que es un lugar amplio y, por ende, sus habitantes se sienten cómodos y seguros, pues, por lo general, se asocia la casa con nociones de seguridad y protección. En palabras de Gastón Bachelard, "es nuestro rincón del mundo" (1985, p. 34); de igual manera, es un lugar que puede entenderse como centro de arraigo y apoyo del hombre. Entre el marcharse y el regresar a la casa (Bollnow, 1964), las relaciones espaciales del hombre se configuran:

La casa es el lugar donde nace el conocimiento del mundo, porque el sentido de casa también es el exterior, es la constante relación entre entrar y salir, es el territorio mismo como un entre, como parte de; es donde se forma el individuo en su condición existencial de lo propio. Él cuida de sí como un cuidado del cuerpo, del espíritu y del saber. (Sañudo, 2013, p. 225-226).

Pero la percepción que hay sobre la casa en la novela es contraria a esta concepción, al estar habitada por tantas personas se manifiestan ideas de incomodidad y de falta de espacio "pues para que todos vivan dentro de la casa, hace falta que haya uno, por lo menos, metido en un armario" (Rosero, 2011, p. 9). La protección y seguridad que parecen propias de este espacio primario se convierten en el relato del protagonista -el Desnudo- en miedo, zozobra y desprotección. La casa deja de ser su "rincón del mundo", no hay un arraigo al lugar:

El hombre, en la tierra, pierde su lugar de arraigamiento, porque no se encuentra especialmente ligado a ningún lugar. Se convierte en un eterno fugitivo en un mundo que lo acosa y los amenaza. Ahí está verdaderamente el peligro del hombre moderno. (Bollnow, 1964, p. 462).

Las amenazas provenientes de los vestidos, que se dan de forma directa en la calle, logran traspasar las barreras de la casa, y son experimentadas por sus habitantes, aunque los niveles de agresión sean diferentes o de menor grado. Esto se puede ejemplificar con las "fiestas" celebradas en la casa -organizadas por y para los vestidos-, que evidencian la subordinación a la que los miembros de la casa están sometidos y además permite entender el paso de la casa como lugar que resguarda a sus integrantes de las adversidades a un lugar donde ellos pueden simplemente dormir y comer.

La relación entre desnudos y vestidos dentro de ese espacio está enmarcada por la necesidad imperante de satisfacer por parte de los primeros las exigencias de los segundos respecto a la alimentación y a la diversión. Para el Desnudo, los vestidos comprenden que ellos están "dispuestos a agasajarlos" (Rosero, 2011, p. 32) y por tal razón se muestran condescendientes, quizá por ello las relaciones lleguen a tener un tono distinto, más blando, la importancia del halago y de sentirse atendidos también aleja las ideas negativas que tienen los vestidos respecto a sus subordinados. Puede pensarse que durante esas "fiestas" se establecen momentos de igualdad, pero siempre hay una prevención frente al otro, los desnudos temen no satisfacer a los vestidos y los vestidos temen sentirse en igualdad de condiciones que sus víctimas, por eso, a pesar de tener la libertad de desnudarse no lo hacen completamente

[...] pues ellos mismos, si quisieran, podrían desnudarse y caminar así, desnudos, en sus casas, o en las calles, si eso desean... Pero no lo harían nunca; incluso en nuestra casa suelen desvestirse a medias; siempre tienen puesto algo, la camisa, un pantalón, o los zapatos; acaso no desean sentirse y contemplarse semejantes a nosotros. (Rosero, 2011, p. 45-46).

La importancia de este lugar, para los desnudos en general, reside en que de cierta manera los resguarda de los peligros de la calle, pero esa tarea se ve quebrantada con la presencia continua de los sentimientos de zozobra y de miedo. Sentimientos generados por la inminente salida de la casa de unos u otros, por la presión ejercida por los cocineros, por la presión de agradar y no cometer ningún error que pueda molestar a los vestidos durante las fiestas. En este sentido, el filósofo Martin Heidegger, con respecto a la habitabilidad de las viviendas construidas en el periodo posterior a la Segunda Guerra Mundial, a pesar de sus comodidades amplitud o buena distribución-, se pregunta lo siguiente: “'Albergan ya 
en sí la garantía de que acontezca un habitar?" (1994, p. 128), ya que para él, el habitar es entendido más allá del simple alojamiento y dentro de este se conjugan elementos como el abrigar y el cuidar. Esa misma pregunta puede trasladarse a la situación ficcional de la novela ¿es posible que los miembros de la casa la habiten verdaderamente?, ¿o es apenas un lugar donde se sienten menos vulnerables?

Ahora bien, los desnudos no se encuentran ligados de ninguna manera a ese lugar que llaman "casa". Las horas transcurren y ellos, en medio del desespero provocado por el deseo de comer, ignoran a sus compañeros y la bajeza de la situación que viven. La cotidianidad de sus vidas les impide reflexionar sobre esa falta de relación íntima con el sitio que ocupan, queja constante del Desnudo: "[...] los de esta casa no piensan en otra cosa que en comer" (Rosero, 2011, p. 32-33). Nos encontramos frente a un lugar que está muy alejado de lo que se supone debería ser una casa, aunque la llamen así, y llegamos a esa conclusión gracias a lo que el Desnudo expresa frecuentemente.

Por otro lado, la puerta, como se entiende por lo general, contribuye a que la casa no sea una cárcel, pues, a través suyo, quien habita la casa puede dejar su espacio y salir al mundo en total libertad, y al mismo tiempo cumple una función de control de ingreso a la casa. No es así en la casa de la narración: primero porque los que la habitan no deciden quién entra y sale, $y$, segundo, porque la puerta es controlada siempre por los vestidos, que se encuentran en el exterior.

La puerta, siempre cerrada y fuera del control de sus habitantes, refuerza el nuevo significado del lugar, pues no hay libertad de movimiento ni decisión, "acaso esta casa fue también una cárcel para su primera habitante, ¿por qué no? Acaso con esa misma mujer empezó la cárcel” (Rosero, 2011, p. 50). Esta acotación del Desnudo, referida cuando trata de encontrar su punto de origen como Desnudo, en la que identifica ese lugar como una cárcel, exalta la falta de libertad. Para Bollnow (1969), "aquel que cierra personalmente su puerta conserva su libertad, más aún, experimenta su libertad de modo singular, pues conserva la posibilidad de abrir la puerta nuevamente cuando quiera" (p. 143), pero aquí no existe esa posibilidad de salir libremente, más bien el cruzar la puerta se entiende como una obligación para cumplir con ciertos deberes, y también como un riesgo para la integridad de quien lo hace.

Las características que encarna la casa y su habitabilidad no se manifiestan en el lugar que recibe ese nombre en la narración, más bien la casa genera sensaciones de inseguridad y desamparo en sus habitantes. El significado de casa propuesto por Bacherlard va a trasladarse a un lugar con características físicas muy diferentes, y permitirá entender la manera en que el hombre resignifica el lugar que habita a partir de sus vivencias.

\section{El armario: refugio, protección y habitar}

$$
\begin{array}{r}
\text { Yo necesito la inmediata posibilidad de escape, pues, } \\
\text { ¿no puedo ser atacado a pesar de toda mi vigilancia } \\
\text { en el punto más inesperado? Vivo en paz en lo más } \\
\text { profundo de mi casa, y entretanto se me aproxima } \\
\text { sigilosamente el enemigo. } \\
\text { La construcción, FRANZ KAFKA }
\end{array}
$$

El segundo lugar de análisis se configura teniendo en cuenta la experiencia del Desnudo. Al Armario se le otorgan las características y las funciones de una casa: "Podría asegurar que mi casa es este armario" (Rosero, 2011, p. 9). Este pequeño "escondite" ubicado en una de las esquinas de la gran casa va a encarnar todas esas características referentes a la protección, y quizá, al habitar como "[...] tener un puesto fijo en el espacio, pertenecer a tal lugar y estar arraigado en él” (Bollnow, 1964, p. 466).

A pesar de la existencia de más buhardillas o escondites dentro de la casa, el Desnudo ha elegido ese lugar en particular para pasar sus días debido a su ubicación (está cerca de una de las cocinas mayores, por lo tanto es un espacio cálido), y a pesar de ser un lugar estrecho e incómodo a simple vista, al protagonista parece no importarle: “[...] en esta vivienda respiro tranquilo, no existe el frío [...] tengo más espacio que quienes habitan por fuera" (Rosero, 2011, p. 11). Esta afirmación se relaciona con el cuestionamiento de Martin Heidegger sobre lo incondicional de la amplitud y la comodidad para que acontezca el habitar, pues la casa es un lugar grande y puede parecer cómodo respecto a algo tan estrecho como un armario. Sin embargo, quizá la cantidad de personas que en ella están y otros elementos han llevado a que el protagonista separe a este lugar del concepto de casa como tal, para otorgárselo al armario. Él siente que pertenece al armario, ese es su punto fijo, su centro, lo que no ocurre con la casa.

La primera característica que convierte a este sitio en una casa para el protagonista es la sensación de protección. El Desnudo ha encontrado en el armario un lugar donde estar seguro y evitar el encuentro con las personas que viven dentro de la casa (los desnudos y los cocineros) y los visitantes (los vestidos). La protección y la seguridad son unos de los principales elementos sobre los cuales justifica su presencia dentro de este, lo que ocurre fuera, en la casa, que tiene ver con la guerra por la comida, quejidos, ataques, las miradas acusadoras de los cocineros, la exposición ante los vestidos en las "fiestas" y lo que conlleva: burlas, humillaciones e incluso golpes, son para el Desnudo acontecimientos que no desea vivir y que lo ponen en peligro, así que el Armario "de ese modo [...] confiere un apoyo para resistir a todos los ataques del mundo exterior"2 (Bollnow, 1969, p. 124). Mundo exterior que encarna la casa $y$, por supuesto, la calle.

2 En esta cita, Bollnow hace referencia a uno de los elementos relacionados con la casa y su habitabilidad. 
Ese escaparate para abrigarse del mundo asume ese papel a partir de las experiencias que ha tenido el protagonista cada vez que fue obligado a abandonarlo. Como ejemplo es posible tomar lo ocurrido durante una de las tantas fiestas ocurridas en la casa, el Desnudo decide salir de su armario y de inmediato es abordado por un grupo de vestidos que escudriñan cada centímetro de su cuerpo con la mirada, posterior a esto hacen burlas respecto a su delgadez, al brillo inusitado de sus ojos, a lo largo de sus cabellos y a la claridad de su piel:

Un visitante dijo una vez, al descubrirme "¿quién es este muerto que camina?" Y se echó a reír a carcajadas, "no tiene piel, es un esqueleto" dijo asfixiado de la alegría [...] lo asombró el tamaño de mi cabeza, desaprobó mis uñas, se espeluznó del largo de mi pelo (que llega a mis tobillos). (Rosero, 2011, p. 35).

Ese mismo visitante lo toma de la mano y lo acerca a un grupo de vestidos, quienes tratan de hacer que se mire en un espejo, no lo logran, y deciden interrogarlo. Las preguntas las hace una vestida:

- ¿Cuántos años tienes?

-No estoy seguro, es probable que tenga cien años, o quinientos, o sólo un año de nacido; nunca he logrado determinarlo con certeza.

- ¿Eres sincero? Preguntó ella, la voz húmeda.

- $\mathrm{Si}$-dije-. Eso creo.

-Te estás burlando de nosotros - gritó uno de ellos, con más admiración que cólera. (Rosero, 2011, p. 39).

Continúan las preguntas que incomodaban al Desnudo, pero cuando alguien decide escudriñar "en el secreto más oculto" (Rosero, 2011, p. 39) de su cuerpo, reacciona violentamente, se siente vulnerado, trata de huir en medio de una exclamación desesperada, es perseguido, hasta que una vestida aboga por su libertad, y este logra ingresar de nuevo al armario de donde decide nunca más salir cuando los vestidos estén dentro de la casa.

Y pude así llegar hasta el armario y sacar de un solo tirón al primer escondido amodorrado que atrapé y ocupar un sitio en la oscuridad de toda mi vida, mi armario, donde a nadie le interesa escudriñar en el vello de mis sexos. Desde esa ocasión he procurado no volver a salir cuando hay fiesta, o visita, a pesar del hambre; duermo noches y días enteros, con la esperanza de que la memoria de los vestidos me borre para siempre de sus venganzas. (Rosero, 2011, p. 40).

En el ejemplo anterior, se pone de relieve la manera como esa relación de entrar/salir o adentro/afuera y la experiencia que vive el protagonista determinan el significado que él mismo le da a los lugares. El hombre para sobrevivir necesita cobijo, y aquí no se trata de encerrarse, resulta necesario regresar a la seguridad "[...] cuando ha cumplido sus tareas en el mundo, tiene que tener la posibilidad de volver al amparo de su casa” (Bollnow, 1964, p. 129). Sí el Desnudo no hubiese experimentado lo que le ocurrió al salir del armario, no habría dado a ese "escondite" tal sentido de amparo.

Un segundo elemento que permite identificar al armario como una casa es la noción de tranquilidad y de paz. La amenaza se desvanece para el Desnudo cuando está dentro. Esa sensación de amparo puede estar correspondida en un primer momento, por las barreras físicas propias del armario (sus tres lados y la puerta), estas evitan el ingreso de cualquier extraño sin la permisividad de quien lo habita.

Pero, más allá de la separación física, la sensación de amparo se relaciona también con cierto espíritu de tranquilidad (Bollnow) que proporciona el interior del lugar que se habita, en este caso, el armario. Volvamos a la referencia anterior de la novela "[...] mi armario, donde a nadie le interesa escudriñar en el vello de mis sexos [...]". Se puede observar que únicamente allí (cuando está solo) es posible sentirse tranquilo y liberado de miradas escudriñadoras, es el lugar donde nadie le pregunta por sus dos sexos, por su origen, o por el brillo de su mirada. Pero, esa sensación de amparo relacionada con la seguridad también es posible gracias a que él puede observar por un orificio - hecho por él mismo-lo que ocurre fuera del armario, con la suerte de que nadie sabe que él lo hace; o en palabras de Otto Bollnow (1969), "ver sin ser visto, principio fundamental de un cuidadoso aseguramiento de la vida" (p. 147), principio tomado totalmente por el Desnudo.

Por ello, es importante analizar este componente del armario, el orificio puede compararse con la función de una ventana. Bollnow (1969) expone que dentro de las misiones de la ventana, entre las más sencillas, "se encuentra la de permitirnos observar el exterior desde dentro” (p. 117), y esa observación que a simple vista parece sencilla, establece también una comunicación con el exterior, comunicación mediada por la mirada, "la ventana también posee un efecto aislante, pasamos a través de la puerta, a la ventana (en su calidad de Augentor = 'puerta para los ojos') sólo la atraviesa la mirada; nosotros permanecemos en el interior" (Bollnow, 1969, p. 149). Esa oportunidad de estar en el exterior de una manera diferente, casi incógnita, le es dada al protagonista: "sólo salgo a través de mi ventana. Esta ventana soy yo, dando pasos" (Rosero, 2011, p. 87). Entonces, la ventana se puede entender como comunicación, pero ahora se le agrega un nuevo significado, a través de ella el Desnudo obtiene cierta ventaja frente a los extraños, y sus posibles ataques, como se observa en el siguiente comentario del Desnudo sobre los encuentros que tiene con los cocineros, dentro del armario:

Y cuando abren de improvisto la puerta del armario, creyendo sorprenderme (ya los he visto desde mi ventana) inquieren escrupulosamente mi fisionomía, husmean cada rincón del armario, y luego sonríen, dudosamente. Yo vuelvo a fingir un rostro de idiota [...]. (Rosero, 2011, p. 72). 
Ventaja que sin duda obtiene a partir de la ventana, y que fortalece la noción de seguridad que ofrece este espacio, "[...] después me olvidan, y yo sigo escondido, y así he logrado que las uñas de mis manos sobrevivan a las tijeras y nadie sospecha que tengo en realidad cuchillos en las manos" (Rosero, 2011, p. 73). El manejo de las situaciones riesgosas, a partir de la mirada, han servido para que el Desnudo, entre otras cosas, cuide las uñas de sus manos afilándolas constantemente hasta volverlas tan filosas como cuchillos. Esto no sería posible sin el espacio de distancia con el mundo exterior, que le ha permitido analizar y reflexionar sobre su situación y la de los demás Desnudos

Para terminar este apartado, resulta necesario resaltar de nuevo la importancia de la relación de la casa con la idea de habitar. No es imperativo contar con un espacio grande y cómodo para sentir que ese espacio es una casa, para descubrir en este las características de protección, amparo y seguridad, por lo que el armario, y su aparente precariedad, encarna para el protagonista todas esas funciones, lo que no ocurrió en el espacio de la casa como tal:

Bastaría incluso un rincón modesto en caso de necesidad [...] lo esencial es un espacio privado que esté a disposición del hombre y que ofrezca una protección contra las inclemencias del tiempo y contra la aproximación no deseada de personas extrañas. (Bollnow, 1964, p 486).

Y el armario fue ese lugar a disposición del hombre, del Desnudo, de su necesidad de protección y resguardo, de su necesidad de encontrar su centro para reflexionar y recuperar fuerzas ante sus salidas al mundo.

Salir significa para el Desnudo arriesgarse y perder la tranquilidad; el paso que lo lleva fuera de su refugio, cruzar el primer umbral de manera voluntaria que lo comunica con la casa es un riesgo que debe evitar porque sabe qué le puede suceder al enfrentarse con las personas que la habitan y sus visitantes, su experiencia le indica con certeza los peligros de estar allí. Pero hay un espacio fuera de la casa que desconoce, un espacio del que ha oído hablar gracias a los que lograron sobrevivir, del cual no tiene certeza y al que decide voluntariamente no entrar: la calle.

\section{La calle: miedo, inseguridad y violencia}

Los vestidos han convertido la calle en un "locus temblis" para los Desnudos: un lugar degradado y hostil. LEÓN Y LÓPEZ, 2006, p. 226

El último espacio presente en la novela y que se incluye en este análisis es la calle. Este espacio es entendido, por parte de los Desnudos y del protagonista, como el espacio más hostil y violento, lo que no ocurre para los vestidos, pues allí se dan actividades comunes como paseos o juegos. La "normalidad" se ve interrumpida solo cuando un desnudo transita en la calle, en esos momentos se desatan una serie de comportamientos violentos sobre ese desconocido que no encaja con los demás.

Para el análisis de las relaciones que se presentan en este lugar, se parte de la noción de extraño manejada por Richard Sennett (1975), en concordancia con lo que él ha denominado búsqueda de pureza, cuyo efecto

[...] es crear en las personas un deseo de purificación de los términos en que ellos se ven por comparación con otros. El empeño implicado es un intento de forjar una imagen o una identidad que fragüe, unifique y filtre la amenaza de los experimentos sociales. (Sennett, 1975, p. 32)

Para Sennett, ese deseo de purificación puede relacionarse en un principio con una característica de la adolescencia, ya que en esta etapa la persona tiende a "purificar su propia identidad ante los ojos de los demás [...]" (1975, p. 33) y da por supuesto los significados de la experiencia sin sobrellevarla activamente, ocasionando que en ella sobreviva un cierto temor por lo que está fuera de sus conocimientos o imágenes (relacionadas consigo mismo), o en otros términos "[...] es para algunos [...] el anhelo de forjar una imagen propia tan clara e inequívoca que resulte inmune al mundo exterior" (Sennett, 1975, p. 32). Luego, ha logrado traspasarse a una estructura comunitaria, en la que se mantiene el impedimento de vivir una experiencia social, relacionado con la creencia en amenazas externas que pueden socavar la identidad (en este caso, una identidad común), y con cierto miedo a enfrentarse a otras formas de identidad.

Los vestidos encarnarían, así, a esos buscadores de pureza (Sennett), pues estos han logrado fortalecer una idea de identidad común y de manera categórica reaccionan contra esa otra forma de ser o estar, propuesta por los desnudos. En el encuentro callejero es posible observar cómo se manifiesta esa imposibilidad de experimentación social con los desnudos por parte de los vestidos:

Es fácil explicar porque [sic] varios de nosotros no salimos a la calle mientras hay fiesta. 0 porque no se nos envía a casa de nadie: nadie quiere ver desnudos en la calle, y mucho menos en su casa [...]. Hay pánico. Miedo. Escalofrío. No precisamente porque nos aterre andar desnudos, sino porque ellos mismos, los de afuera, parecen ser los aterrados, y entonces procuran en lo posible aterrarnos a nosotros, agrediéndonos de distintas maneras. (Rosero, 2011, p. 12).

Como se observa en la cita anterior, se identifica claramente una de las diferencias más preponderantes en la narración, y que sirve para nombrary categorizar a los personajes, el uso o no de ropa. Para los vestidos no usar ropa quiebra una de sus reglas sociales, y representa una forma de peligro para su organización; aterrarse porque el otro es capaz de salir desnudo a las calles es uno de los síntomas, y también la manera 
como ese terror se convierte en agresión, sobre este punto se volverá más adelante. Estar vestidos, por otra parte, podría ubicarse dentro de eso que anteriormente se mencionaba como identidad común o grupal, pero a esa identidad se le agregan más elementos, entre ellos el tener un solo sexo o la preponderancia de un elemento racional en todas las actividades que desarrollan a diario:

Las vestidas emplean los entremeses para hablarnos de lo que son las aves y los animales, nos dan lecciones generales de lectura y escritura, de una historia y geografía que son sólo de ellas [...] nos muestran grandes retratos de animales y se regodean en nuestro asombro, nuestras preguntas las hacen reír hasta las lágrimas, "pero qué imbéciles son”, dicen. (Rosero, 2011, p. 44).

Ese sentimiento de identidad común manejado por los vestidos facilita la idea de entender a la comunidad como un todo: "Las personas trazan un retrato de quiénes son, que las aglutina como si fueran una sola, con una colección definida de deseos, antipatías y metas" (Sennett, 1975, p. 57). Así que hay una antipatía común hacia los desnudos y lo que representan, unos deseos de progreso acompañados de un deseo de control total de todas las situaciones, una necesidad de inventar nuevas formas de tortura para los desnudos que pisan las calles, "y como ellos son tan recursivos en toda clase de artefactos de tortura cada vez más refinados, dirigidos al encuentro de una perfecta conjunción entre la más expectante lentitud y el más intenso dolor" (Rosero, 2011, p. 13), todo esto acompañado con la característica de estar siempre vestidos, aunque sea con un par de medias.

La acción de crear nuevos artefactos de tortura va acompañada de un discurso, de igual manera, violento, en el que los vestidos, como hombres que ostentan la razón -hombres de ciencia, de leyes y de letras-, ostentan también el poder en cuanto a la organización social y política, mientras que los desnudos ocupan el lugar del insignificante. Progreso y poder van de la mano, la idea de la civilización como un estadio superior de lo que se conoce como lo bárbaro es lineal en el comportamiento de los vestidos.

Manejar a su antojo todo cuanto está a su alrededor, a partir de la posibilidad que les da el estar afuera y conocer, permite relacionar a los vestidos con lo "civilizado", la diferenciación más básica, el uso de ropa, lo corrobora. A partir de esa "superioridad" que dicen ostentar por encima de los desnudos, realizan prácticas en las que siempre están de por medio el ejercicio de poder, así como Adorno y Horkheimer exponían en su Dialéctica del iluminismo (1992): "La barbarie no queda neutralizada como contraconcepto de la civilización sino que la propia modernidad es barbarie al establecer una afinidad perversa entre la razón instrumental, el dominio de la naturaleza y el exterminio selectivo del hombre [...]" (citados por Beriain, 2005, p. 112). El conocimiento es utilizado aquí para someter y las experiencias en la calle de manera directa dan cuenta de ese sometimiento, hay un grado de barbarie por parte de los "civilizados", los vestidos, a pesar de que ellos consideren que los barbaros son los otros, hay un ejercicio de barbarie en manos de los que parecen racionales y civilizados (imparten cátedras de comportamiento e higiene, poseen conocimientos científicos avanzados, planifican sus vidas) y, tal como lo afirman Adorno y Horkheimer, nos encontramos con un panorama en el que el dominio bajo el pretexto de un único saber y una única verdad llevan a nuevas formas de violencia, más estilizadas, pero violencia al fin y al cabo.

Los vestidos, como un todo, evitan lo que no corresponde al orden que ellos establecen, porque sienten amenazada su estabilidad, es por eso que los desnudos encarnan el desorden, lo incontrolable, lo diferente, lo irracional. Establecer un diálogo en igualdad de condiciones con ese desorden resulta imposible para los vestidos, ya que ese todo se puede desquebrajar, en palabras de Sennett (1975):

Las experiencias públicamente dolorosas, las situaciones sociales desconocidas llenas de posible sorpresa y reto, pueden ser evitadas gracias al común consenso de una comunidad en creer que ellos conocen ya el significado de estas experiencias y han extraído las lecciones de ellas conjuntamente. (p. 58-59).

Ese consenso permite que todos experimenten las mismas sensaciones al encontrarse un desnudo en la calle, la violencia y la humillación son vistas como algo normal, incluso necesario, para darle una lección a quien se atreve a perturbar la tranquilidad aceptada, hay un consenso sobre lo que se debe hacer para mantener la jerarquización. De manera metafórica, el Desnudo expone cómo se le atribuyen beneficios medicinales al ejercicio de torturar desnudos en las calles:

La positiva respuesta de estos cuerpos añosos y desmadejados ante cada ejecución ha sido tan satisfactoria, que los mismos médicos que habitan entre vestidos no dudan en recomendar por unanimidad la tortura como remedio incontestable para el reuma, por ejemplo, la obstrucción intestinal, la insensibilización del asma [...] el histerismo y, fundamentalmente, la aburrición. (Rosero, 2011, p. 16).

Ya es posible identificar claramente una reacción común frente a los "otros", y para que existan unos "otros", debe existir un "nosotros" fortalecido por la idea del todo, esa idea en los vestidos permite pensar que entre ellos todo está bajo control, porque como comunidad se pertenecen unos a otros, por lo tanto responden igual frente a cualquier situación. Para Sennett (1975), "el sentimiento de 'nosotros', que expresa un deseo de ser semejantes, es un modo que tienen los hombres de evitar la necesidad de analizarse mutuamente más a fondo [...]" (p. 60). En este sentido, si el hombre se entrega completamente a la idea de que está inserto en un todo, en el cual todo ya está dicho, como en el caso de las relaciones vestidos-desnudos, elude un análisis del porqué reacciona de tal manera a un acercamiento a lo que le es ajeno, "[...] en vez de esto los hombres se imaginan que lo conocen todo unos de otros, 
y su conocimiento se convierte en una convicción de que deben ser lo mismo" (Sennett, 1975, p. 60); cuando no son lo mismo, se engendra un rechazo, que puede ser violento.

Por tanto, la calle, el lugar de este encuentro, engendra de una forma directa la exclusión a la que se somete a los desnudos ${ }^{3}$, pues la comunidad de los vestidos, toda, rechaza su presencia. Esa exclusión y rechazo se manifiesta con violencia: "Algunos nos lanzan barro a manotadas, o piedras filudas; otros nos escupen, nos empujan como pelotas de juego, nos elevan, nos entierran, nos preparan, en fin, a la tortura, si es que están de buen ánimo [...]”. (Rosero, 2011, p. 18), sin contar los secuestros y los múltiples oficios que son obligados a realizar. Para Sennett, "[...] las comunidades cuyos componentes humanos se sienten vinculados mutuamente en virtud de su similitud están polarizadas" (1975, p. 64). Por lo que un grado mínimo de diferencia va en contravía de la comunidad y merece ser eliminado o separado, en la siguiente cita, se puede observar cómo es castigado un desnudo por el hecho de serlo:

A un desnudo lo amarraron al tronco de un saúco y lo dejaron ahí durante días, y en lugar de agua le dieron a bebe vinagre, y de tanto en tanto lo lanceaban con unos palos embadurnados en acíbar. Le pusieron un rótulo, colgando en el cuello: 'Por desnudo, y se puede asegurar que ese rotulo fue, por poco, su epitafio. (Rosero, 2011, p. 19).

El rótulo colgado en su cuello habla por sí mismo, no tuvo otra culpabilidad para merecer tal castigo, sino el simple hecho de estar desnudo, y no manejar el mismo código de comportamiento de sus verdugos. Existe en el comportamiento de los vestidos intolerancia y una incapacidad para manejar la tensión que acarrea el encuentro con quienes no están en la estructura de su todo comunitario:

Al existir, por tanto, tan poca tolerancia para el desorden en sus propias vidas, y por haberse encerrado tanto en sí mismos de modo que no poseen tampoco ninguna experiencia del desorden, la erupción de tensión social se transforma en una situación en la que los métodos fundamentales de agresión. Fuerza violenta y represión parecen ofrecer ya no solamente justificación, sino seguridad del vivir. (Sennett, 1975, p. 65).

La agresión y la violencia que ejercen los vestidos es justificada por la creencia de que los desnudos representan toda clase de peligros y riesgos para sus vidas. La salida del desnudo a la calle causa exaltación, indignación, desorden; pero su presencia resulta necesaria, pues la diferencia del otro y su supuesta peligrosidad reafirma la posición y el deseo de la comunidad de purificarse a sí misma:"[...] y así estamos, estigmatizados,

\footnotetext{
3 También es posible identificar la exclusión que sufren los desnudos en el escenario de la casa, pues en este lugar están encerrados y sometidos a diferentes vejámenes por parte de los vestidos. Se privilegia la calle para el análisis de esta categoría porque allí se desarrollan acciones de violencia directa, y el temor ante un ataque lo experimentan todos los desnudos, incluido el protagonista.
}

nos usan y desusan al derecho y al revés, y después gritan que nos larguemos a casa, porque de todas maneras les hacemos falta, vivos, nosotros y nuestros dos sexos y nuestra casa [...]" (Rosero, 2011, p. 29).

Es indiscutible que la calle se ha convertido, como lo señala la cita que da inicio a este apartado, en el lugar más temido para los desnudos, y que ese significado ha sido posible gracias a las actuaciones de los vestidos, que, como comunidad, busca legitimarse a sí misma excluyendo y oprimiendo a lo que considera diferente.

\section{Hombre y espacio en la novela}

La experiencia del hombre frente al espacio, en la que se apremian sus percepciones, sus sentimientos y sus vivencias, genera una discusión fructífera entre la espacialidad humana y la configuración espacial en el texto narrativo. En su interacción con el espacio, el hombre puede experimentar sentimientos de aprehensión o de rechazo, puede generar significaciones variadas dependiendo de la manera en la que entiende o vive el lugar, y la novela, en este caso, realiza una mirada a la complejidad de esas percepciones.

A partir de la importancia que tiene la experiencia espacial del hombre, la obra literaria permite realizar un acercamiento a la vivencia espacial del otro, es decir, la del autor, y a partir de allí la realización de una construcción de significado que incluye las construcciones hechas por el lector, o en palabras de Yi-Fu Tuan: "La literatura, más allá que las investigaciones procedentes de las ciencias sociales, nos proporcionan una información a la vez detallada y matizada sobre como los individuos perciben sus mundos [...]" (2007, p. 74). Esas expresiones del mundo que son sutilmente diferentes permiten reconocer la singularidad de las experiencias personales.

Ahora bien, la vivencia del espacio, dentro de la literatura ha estado presente constantemente y ha sido trabajada de diversas maneras, ya sea que la obra parta de una ciudad especifica -el Buenos Aires de Sobre héroes y tumbas (1961), de Ernesto Sábato- o de la vivencia de una ciudad cualquiera (imaginada o no) que encarna las características de un momento histórico - el Macondo de Cien años de soledad (1967) de Gabriel García Márquez-. Lo importante de estas representaciones recae en las relaciones socio-espaciales que allí se manifiestan, pues más allá de la descripción de una estructura física, de avenidas o de monumentos, lo sobresaliente de esas ciudades es lo que sus habitantes experimentan a diario, las relaciones que subyacen entre los hombres y entre el hombre y el espacio. Por tanto, aunque en el ámbito "objetivo" del espacio, es decir, la realidad inmediata que se percibe, se encuentran y se prevén situaciones, como ciertas rutinas de desplazamiento, la organización de la estructura física (alcantarillado, iluminación), entre 
otras, la literatura se permite indagar el trasfondo de la fachada espacial, tomando en cuenta no solo lo factual y cuantificable, sino el sentido del trasegar del hombre dentro de su espacio.

La mirada sobre la cotidianidad del hombre permite observar elementos importantes para entender las configuraciones espaciales, de igual manera las relaciones humanas surgidas dentro de la novela, en medio de espacios específicos - casa, calle y armario-, dan cuenta de la forma como la organización en general del espacio afecta las relaciones con los otros y reconfigura ideas y significaciones sobre este. En el análisis de la novela Señor que no conoce la luna, se develan elementos importantes de la relación entre el hombre y el espacio, partiendo de la experiencia cotidiana de cada uno de los personajes. Esta vivencia cotidiana incluye entre sus elementos el carácter de las relaciones sociales que se experimentan en ciertos lugares, determinantes en la construcción de las redes de sentido que tejen quienes viven intensamente el espacio.

\section{Referencias}

Adorno, T., y Horkheimer, M. (1992). Dialéctica del iluminismo. Buenos Aires: Sudamericana.

Aínsa, F. (2006). Del topos al logos, propuestas de geopoética. Madrid: Iberoamericana.

Bachelard, G. (1985). La poética del espacio. México: Fondo de Cultura Económica.

Beriain, J. (2005). Modernidades en disputa. Barcelona: Anthropos.

Bollnow, O. (1964). El hombre y su casa. Eco, Revista de la Cultura de Occidente, 11, 452-493.

Bollnow, O. (1969). Hombre y espacio. Barcelona: Labor.

Heidegger, M. (1994). Construir, habitar, pensar. En Conferencias y artículos [Trad. Eustaquio Borja]. Barcelona: Odós.

Kafka, F. (1999). La construcción. En La muralla china, cuentos, relatos y otros escritos. Madrid: Alianza.

León, A., y López, E. (2006). Señor que no conoce la luna: la apuesta escéptica de Evelio Rosero Diago. Análisis: Revista Colombiana de Humanidades, (70).

Lindón, A. (2000). La vida cotidiana y su espacio-temporalidad. Barcelona: Anthropos. 
Rincón, P. (2007). Hombre y espacio. Otto Bollnow (1969). Análisis crítico. Universidad de los Andes. Recuperado de http://servidor-opsu.tach.ula.ve/ profeso/maldo_h/l_analis/hombre_esp.pdf

Rosero, E. (2011). Señor que no conoce la luna. Bogotá: Planeta.

Sañudo, L. (2013). La casa como territorio. Una nueva epistemología sobre el hábitat humano y su lugar doméstico. Revista Iconofacto, 9(12), 214-231.

Sennett, R. (1975). Vida urbana e identidad personal, los usos del desorden. Barcelona: Península.

Tuan, Y. (2007). Topofilia, un estudio de las percepciones, actitudes y valores sobre el entorno. Barcelona: Melusina. 